\title{
The Effect of Gamified Teamwork on Business- related Idea Generation
}

\author{
An Experimental Study
}

\author{
Polina Trusova \\ Manchot Graduate School "Competitiveness of Young Enterprises" \\ Heinrich-Heine-University Düsseldorf \\ Düsseldorf, Germany
}

\begin{abstract}
Innovation providing a competitive advantage to enterprises is based on original ideas usually developed by teams. Therefore, the optimization of idea generation in teams is crucial for the enterprises' competitiveness and survival. The goal of this experimental study is to test whether idea generation in team can be made more effective in terms of quantity and quality through gamification (the use of game design elements in non-game contexts). Based on conservation of resources theory, in the present study gamification was assumed to generate and regulate task-related resources and therefore to increase the number and originality of generated ideas. 170 students divided in 70 teams were asked to imagine themselves to be a management team of a young innovative enterprise during a crisis meeting and to generate solutions for the described problems. 35 teams were randomly assigned to the gamification condition and another 35 teams to the control condition. The number and originality of ideas were evaluated by two independent condition-blind raters and compared between the conditions. Gamification has a large positive effect on the idea number and a medium-sized positive effect on the idea originality. The findings, implications and limitations are discussed.
\end{abstract}

Keywords-enterprise; gamification; idea generation;
innovation; teamwork

\section{INTRODUCTION}

Innovation which is defined as "the multi-stage process whereby organizations transform ideas into new/improved products, service or processes" [1, p. 1334] is usually developed by teams [2], [3] and is considered as a crucial competitive advantage for enterprises [4]. Firms which develop innovative products or services were shown to have a higher market share and achieve higher profits compared to less innovation-driven firms [5] - [7].

At the same time, innovation development is a complex, risky and expensive task [8] - [10]. There are also high requirements for employees such as breaking out of routine procedures, effort coordination and openness for new experiences [11] - [13].

The very first and therefore the key step in innovation development is the generation of a new idea, which is mostly done in teams [14] - [17]. It requires strong effort synchronization, work monitoring and management of the performance pressure [11], [12]. If a team does not succeed at these tasks, the resulting problems like ineffective teamwork for innovation development and conflicts within the team can

Financial support by the Jürgen Manchot Foundation is gratefully acknowledged. threat the enterprise's competitiveness and survival [18] - [20]. A failure to develop an innovative solution is not only problematic for enterprises, who lose an immense amount of invested time and money, but also for the entire economy as innovation drives economic growth and also has a big impact on society [21] - [23].

There are several teamwork methods which are supposed to make teamwork for idea generation more effective. Although brainstorming [24] is used very frequently in the business context [25], [26], in its original version it was found to block idea generation in groups [27] - [29]. As one reason, the delay between idea generation and articulation was identified [28]. A method which overcomes this problem by including phases of working alone is the nominal group technique or NGT [30], [31]. By the NGT rules, discussions and idea exchange between team members are strongly limited temporally and can be carried out only in special work phases. Despite its effectivity, the NGT is seldom used in enterprises because potential participants often do not accept it [32]. One possible reason is that the spontaneous information exchange between team members during brainstorming sessions enhances the perceived (but not the observed) productivity of teamwork. If this exchange is limited, it reduces the so-called illusion of productivity [33], which can lead to the NGT rejection.

This disadvantage of the NGT can be partially compensated by making the procedure of idea generation more informal and enjoyable through gamification, i.e. "the use of game design elements in non-game contexts" [34, p. 10]. Single game design elements, also called gamification mechanics are known from diverse games like sports, tabletop or video games. Points, leaderboards and badges were found to be the most common of them [35]. Although these mechanics existed long before the term gamification was established, they were never combined into one concept in a non-game context and used as widely as it is done today. This makes gamification a new empirical phenomenon of scientific interest beyond the buzz word [35]. Gamification was already proven to enhance students' self-reported learning effectivity and engagement [36], [37], to speed up the solving of a scientific problem through a big non-professional community [38] and to facilitate the recruitment of new employees [39]. As gamification can be implemented without an elaborate and expensive digital platform [40] and used for idea generation and idea competitions in groups [41] - [44], it may also help 
enterprises to efficiently generate innovative ideas in a team without causing high additional costs or personnel efforts. This is particularly relevant for the innovation development process.

Considering the above-mentioned findings, the aim of the present study is to test whether business-related idea generation in small teams can be made more effective in terms of quantity and quality through gamification.

\section{THEORETICAL BACKGROUND AND HYPOTHESES}

\section{A. Team and Innovation-related Teamwork}

Based on previous research, [45] defined a team in organizational context as a collection of individuals who are interdependent in their tasks, share responsibility for outcomes, consider themselves and are considered by others as an intact social entity, embedded in at least one larger social systems and manage their relationships across organizational boundaries. The term team can be considered as a synonym for a group, which does not imply any size limitation, therefore even small groups like dyads and triads can be referred as teams [46], [47]. In some cases, dyads and triads reflects the organizational reality more precisely than larger group, e.g., young innovative enterprises are usually found and led by two to three persons [48].

Teamwork includes the thoughts, feelings, and behaviors among team members interacting toward a common goal [49]. Beyond the collaborative problem solving, teamwork also consists of shared behaviors of team members, their attitudes and cognitions which are necessary to complete current tasks [50], [49].

\section{B. Idea Generation}

The most important outcomes of idea generation sessions are the quantity and quality of generated ideas, therefore the effectivity of such sessions is mainly operationalized by the number and characteristics of generated ideas [51] - [53]. In the present study, the quality of generated ideas is measured by their originality [29], since an original idea can further build a basis of an innovative product and provide a decisive competitive advantage to the enterprise [54].

\section{The Effect of Gamification on Performance}

According to the descriptive theory of Homo Ludens, playing games is a central element of human culture and aims to organize players' experience [55]. A game may fascinate players because it induces an optimal flow state [56]. It also can increase participants' engagement and humor, which positively influence creativity and work productivity [57] [60].

These approaches focus on positive outcomes of play and games only, although in a professional context negative outcomes are also possible [61]. A more detailed explanation which psychological mechanisms may trigger both positive and negative effects of play on work performance can be provided by conservation of resources (COR) theory [62]. On the one hand, playing games can help to create and manage psychological and psychosocial resources through emotion regulation or by maintaining relationships between employees, resulting in the increased work effectivity [61]. On the other hand, playing games can make the participants work less effectively due to the time and energy loss which has to be avoided according to COR theory [62], [61]. This is especially

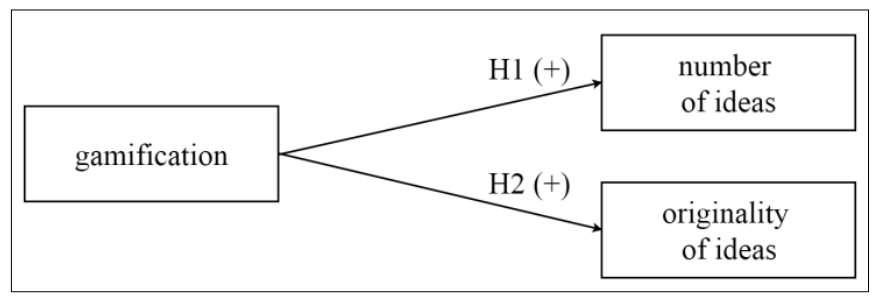

Fig. 1. Experimental hypotheses.

relevant for a task-unrelated game at work like playing table tennis with colleagues. However, gamification mechanics are always integrated into the work task and are therefore not supposed to draw any relevant resources away from work. In accordance to COR theory it can be assumed that gamification should have positive, and not negative effects on work performance. According to idea generation in team, work performance is operationalized as quantity and quality of ideas generated in teamwork. Thus:

Hypothesis 1 (H1): Gamification has a positive effect on the number of ideas generated by small teams.

Hypothesis 2 (H2): Gamification has a positive effect on the originality of ideas generated by small teams.

Both hypotheses are presented in Fig. 1.

\section{METHOD}

The former research on gamification consists mainly of quasi-experiments [63] - [65] or field studies [41], [66]. Reference [35] criticize a wide range of publications because of severe methodological shortcomings like small samples, missing control conditions or results limited to descriptive statistics and user evaluation.

To overcome these problems, the present experiment was designed. In the previous experimental studies on idea generation in teams, open-ended questions like What would happen if everyone had an extra thumb on each hand? without any further restrictions were widely used [67], [33]. They did not pretend to be realistic or easily transferable to the business practice. However, both aspects are important for a potential implementation of gamification in enterprises. Therefore providing a realistic and practically relevant task was aimed in the present study.

\section{A. Participants}

175 university students were recruited. They divided themselves in 72 teams of two or three persons. Written informed consent was obtained from each participant. A pilot team consisted of two persons whose data were not included into the analysis. One participant failed to fill out $27.6 \%$ of the questionnaire, therefore his team consisting of three persons was post hoc excluded from the data analysis.

The data of the remaining 170 students in 70 teams were analyzed. 30 teams consisted of three participants each, 40 teams consisted of two participants each. 34 teams consisted of 
female members only, 27 teams were mixed and 9 teams consisted of male members only. 35 teams were randomly assigned to the experimental and the other 35 teams to the control condition. Participants ranged in age from 18 to 38 years $(M=22.41, S D=3.79) .70 .6 \%$ were female. All participants could choose either a monetary reward of 20 euro or a formal confirmation of their participation needed by psychology students for graduating from the university.

\section{B. Materials and Apparatus}

1) Case study and questionnaire: All written materials were in German. For a realistic crisis meeting simulation a paper-pencil case study strongly related to a situation of an innovative enterprise was developed following an example used in assessment centers [68]. A standard solution consisted of ten ideas and was validated by comparing it to the results of a pilot group. A paper-pencil questionnaire (s. Table I) included demographic items, personality and attitudes scales and a 7-point Likert feedback scale (from $1=$ strongly disagree to $7=$ strongly agree) consisting of seven items. The feedback scale measuring the subjective perception of the task and task instructions was designed especially for the present study. The data from the questionnaire will be considered in a future research project.

2) Materials and technical equipment: In the gamification condition, blank paper moderation cards and moderation cards with a thumbs-up symbol were used. A laptop with a prepared blank file was provided in both conditions. A microphone and a digital video camera were used to record each discussion for analyzing the data in a future research project.

\section{Study Design}

The present study was designed as a single factor betweenparticipant experiment.

1) Independent variable: As the independent variable the experimental condition with levels gamification and control was applied.

2) Dependent variables: The number and originality of the ideas generated by teams were used as dependent variables. Two independent condition-blind raters included all nonredundant ideas generated by all teams in their idea catalogues, compared them to each other and found five principally divergent cases in which they disagreed on whether a team's suggestion is a new idea or whether it should be considered as redundant to any other idea. These cases were discussed and a final idea catalogue consisting of 137

TABLE I. RELIABILITY COEFFICIENTS OF THE QUESTIONNAIRE SCALES IN GERMAN LANGUAGE

\begin{tabular}{|l|l|}
\hline \multicolumn{1}{|c|}{ Scale } & Cronbach's $\boldsymbol{\alpha}$ \\
\hline Big Five Inventory, short version [69] & .72 \\
\hline Internal and external locus control [70] & {$[.58 ; .71]$} \\
\hline $\begin{array}{l}\text { German Arnett Inventory of Sensation Seeking, short } \\
\text { version [71], [72] }\end{array}$ & {$[.49 ; .66]$} \\
\hline Entrepreneurial intention [73] & .97 \\
\hline Feedback scale developed for the present study & .82 \\
\hline
\end{tabular}

ideas in total was created. This idea catalogue built a basis for the further evaluation. In previous research the elimination of useless or unrealistic ideas was based on subjective judgements, which is a reliable method in a well-defined context with clear tasks and limited resources as for example described by [74]. In contrast, in the given case study no strong restrictions such as financial or personnel resources limited to a specific amount were contained. Besides, no obviously absurd idea like recruiting new employees on Mars was found in the sample. For these reasons the idea elimination was considered as unnecessary. The number of ideas generated by each team was counted independently by both raters. The dependent variable number of the ideas generated by team was calculated as follows: for each team, the numbers of generated ideas reported by both raters were added up and divided by two. An idea generated less frequently was more original than an idea generated more frequently in a given sample [75]. The relative frequency for each idea in the sample was calculated by dividing the absolute frequency of its idea in the sample by the total team number in the sample. For instance, if an idea was generated by 35 teams of the 70 teams, its relative frequency was $35 / 70=0.5$. The average relative frequency across all ideas generated by a particular team was calculated by adding up all relative frequencies and then dividing the resulting value by the number of ideas generated by this team. A team's originality score was calculated as 1 (average relative frequency across all ideas generated by a particular team). These calculations were conducted by each of the both raters independently. The dependent variable originality of the ideas generated by team was calculated as follows: for each team, the team's originality scores reported by both raters were added up and divided by two. Krippendorff's $\alpha$ was used as the interrater reliability measurement resulting in $\alpha=0.81$ for the number of generated ideas per team and $\alpha=0.76$ for the originality of generated ideas per team, which is good and acceptable respectively [76].

3) Covariats: The covariats on team level are mean age of team members, sex composition of the team, mean relationship duration within the team in months, team size and mean time in hours per week which team members spend playing diverse games.

\section{Procedure}

All participants received written instructions. Only one team was tested at a time. The experimenter's interaction with the participants was limited to answering their questions at the beginning as close to the written instructions as possible, handing out the materials and stopping the time. The questionnaire was handed out randomly either before or after the case study to each participant. 


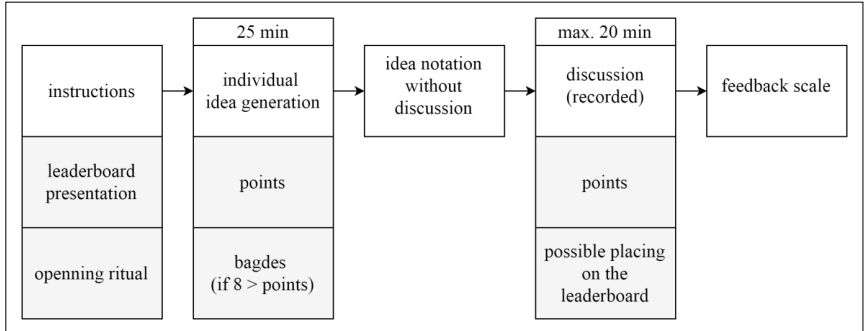

Fig. 2. Experimental phases. Grey rectangles represent gamification mechanics which are relevant for the gamification condition only. The questionnaire was handed out randomly either before or after the case study and is not shown here.

Fig. 2 illustrates experimental phases. In the gamification condition the participants were asked to read the instructions, but not the case study materials yet. A leaderboard consisting of five moderation cards with one of the five best-performing teams on each card and points they achieved in ascending order was presented to the participants. For the first five teams cards with fictitious information were used. The participants were informed that their team can be placed on the leaderboard if it achieves a greater number of points than a team on the leaderboard. Then the participants were asked to follow the opening gamification ritual recommended by [40] for creative tasks, i.e. to hold their palms up for 15 seconds. This position was proven to have a positive effect on attitudes towards new stimuli due to its evolutionary old association with open mind: while receiving something, people hold their hands up, while holding the palms down is a rejection gesture [77], [40]. After the ritual, the work on the case study following the general principles of the NGT [30], [31] began.

Participants were instructed to imagine themselves to be members of a management team of an innovative enterprise during a crisis meeting and to analyze the described problems as well as think of creative solutions. In the first phase, each participant worked on her or his own for 25 min screening the case study materials and taking notes. No exchange was allowed in this phase. The experimenter counted the number of ideas generated by each participant. Each participant was given a moderation card with the number of achieved points equal to the number of generated ideas. These numbers served only as a feedback for the participants and were not considered in the later data analysis. Participants who generated more than eight ideas received a badge of idea generator in form of a moderation paper card with a thumbs-up symbol on it.

In the second phase, each participant was asked to note one idea in turn in a blank file on the laptop without discussing it. Participants were advised to read the ideas that had already been written down by others before writing down their own ideas.

The third phase was limited to 20 min and consisted of a discussion within the team, which was audio and video recorded. The phase was ended prematurely if participants asked for it twice. They were allowed to discuss the noted ideas, eliminate them or develop any further ideas. After the discussion the feedback scale was filled out by each participant.
The experimenter assessed the team's result. One point was given for every idea including both identified problems and suggested solutions and two points were given for every original idea not included in the standard solution. These numbers served only as feedback for the participants and were not considered in the later data analysis. Then the team was placed on the leaderboard if the relevant conditions were met.

In the control condition the opening ritual, points, badges and leaderboard were excluded. All other instructions as well as the case study materials were equivalent to the gamification condition.

\section{RESUlts}

\section{A. Missing Values}

On average, each questionnaire item including demographic items was missed by $0.3 \%$ of the participants $(\min =0 \%, \max =2.3 \%)$. No missing data patterns were found. The missing values were considered to be missing completely at random and were substituted by relevant means.

\section{B. The Number of Ideas}

Fig. 3, Tables II and III show descriptive statistics and correlation coefficients. The contingency between the sex composition of the team and the experimental condition was not significant, Cramer's $V=0.05, \mathrm{p}=0.93$.

A stepwise regression analysis was conducted to test $\mathrm{H} 1$. No violation of normality assumption $(W(70)=0.98, p=0.32)$ and no severe violations of the assumptions of linearity, homoscedasticity and absence of multicollinearity were found.

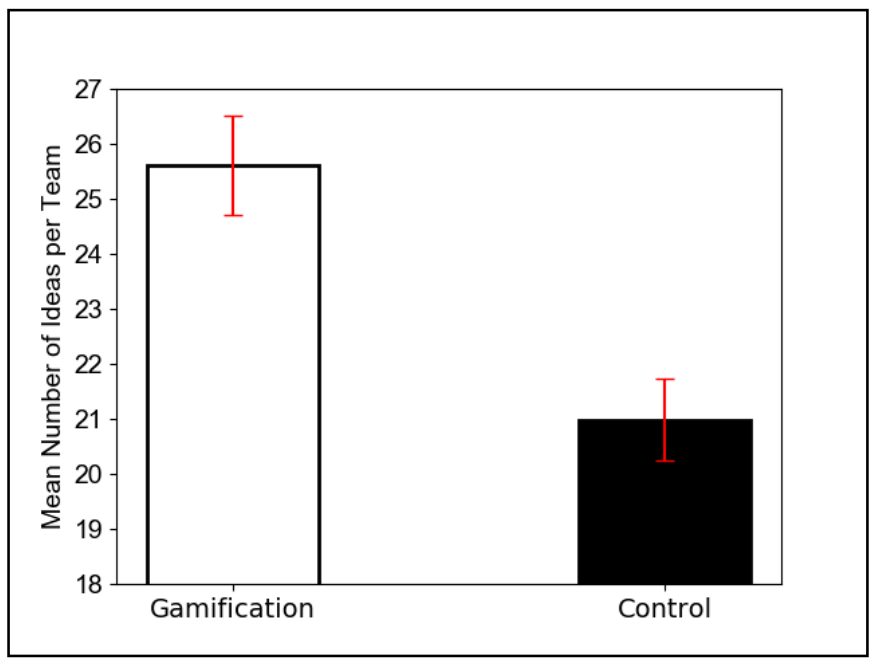

Fig. 3. Mean number of ideas per team for the gamification and control conditions. Significantly more ideas were generated by teams in the gamification condition than in the control condition. Standard errors are represented in the figure by the error bars attached to each column. 


\begin{tabular}{|c|c|c|c|c|c|c|c|}
\hline Variables & $\mathbf{M}$ & SD & 1. & 2. & 3. & 4. & 5. \\
\hline 1. Number of ideas & 23.29 & 5.38 & & & & & \\
\hline 2. Originality of ideas & 0.43 & 0.07 & $0.73 * *$ & & & & \\
\hline $\begin{array}{l}\text { 4. Relationship duration within a team } \\
\text { (month) }\end{array}$ & 26.80 & 50.46 & -0.07 & 0.00 & 0.14 & & \\
\hline
\end{tabular}

TABLE III. CORRELATION OF THE NOMINAL VARIABLES AND RATIO DEPENDENT VARIABLES AND COVARIATS

\begin{tabular}{|c|c|c|c|c|}
\hline \multirow[t]{2}{*}{ Variables } & \multicolumn{2}{|c|}{$\begin{array}{c}\text { Sex composition of } \\
\text { the team }\end{array}$} & \multicolumn{2}{|c|}{$\begin{array}{c}\text { Experimental } \\
\text { condition }^{\mathrm{b}}\end{array}$} \\
\hline & $\eta$ & $\eta^{2}$ & $\eta$ & $\eta^{2}$ \\
\hline Number of ideas & 0.21 & 0.04 & 0.43 & 0.18 \\
\hline Originality of ideas & 0.14 & 0.02 & 0.27 & 0.07 \\
\hline Age of team members & 0.27 & 0.07 & 0.05 & 0.00 \\
\hline $\begin{array}{l}\text { Relationship duration } \\
\text { within a team (months) }\end{array}$ & 0.38 & 0.14 & 0.03 & 0.00 \\
\hline Team size & 0.16 & 0.03 & 0.06 & 0.00 \\
\hline $\begin{array}{l}\text { Gaming time of team } \\
\text { members (h/week) }\end{array}$ & 0.38 & 0.14 & 0.03 & 0.00 \\
\hline
\end{tabular}

\section{TABLE IV. COEFFICIENTS OF REGRESSION ANALYSIS - NUMBER OF IDEAS}

\begin{tabular}{|c|c|c|c|c|c|c|}
\hline \multirow{2}{*}{$\begin{array}{c}\text { Regression statistics } \\
d f\end{array}$} & \multicolumn{3}{|c|}{ Model 1} & \multicolumn{3}{|c|}{ Model 2} \\
\hline & & 5 & & & 6 & \\
\hline$R^{2}$ & & 0.13 & & & 0.32 & \\
\hline Adjusted $R^{2}$ & & 0.06 & & & 0.26 & \\
\hline $\boldsymbol{F}$ & & 1.91 & & & $4.97 * * *$ & \\
\hline$\Delta R^{2}$ & & 0.11 & & & 0.09 & \\
\hline$\Delta F$ & & 1.91 & & & $17.75^{* * *}$ & \\
\hline$f^{2}$ & & 0.15 & & & 0.47 & \\
\hline Variables & $B$ & $S E$ & $\beta$ & $B$ & $S E$ & $\beta$ \\
\hline Constant & $22.45^{* *}$ & 6.79 & & 12.65 & 6.48 & \\
\hline Age of team members & -0.23 & 0.21 & -0.14 & -0.17 & 0.19 & -0.10 \\
\hline Sex composition of the team ${ }^{a}$ & -1.03 & 1.00 & -0.13 & -0.76 & 0.89 & -0.10 \\
\hline $\begin{array}{c}\text { Relationship duration } \\
\text { within the team (month) }\end{array}$ & 0.01 & 0.01 & 0.06 & 0.00 & 0.01 & 0.04 \\
\hline Team size & $3.23 *$ & 1.32 & 0.30 & $3.56^{* *}$ & 1.17 & 0.33 \\
\hline $\begin{array}{c}\text { Gaming time (h/week) } \\
\text { of team members }\end{array}$ & -0.06 & 0.16 & -0.05 & -0.04 & 0.14 & -0.03 \\
\hline Experimental condition ${ }^{b}$ & & & & $4.71 * * *$ & 1.12 & 0.44 \\
\hline
\end{tabular}


As shown in Table V, Model 1 consisting of the covariats only did not explain a significant amount of variance. Model 2 explained a significant amount of variance in the originality of ideas per team over and above the variance explained by Model 1. The maximum VIF value in Model 2 was 1.19. It had two significant predictors: team size $(\beta=0.29, t(63)=2.48$,

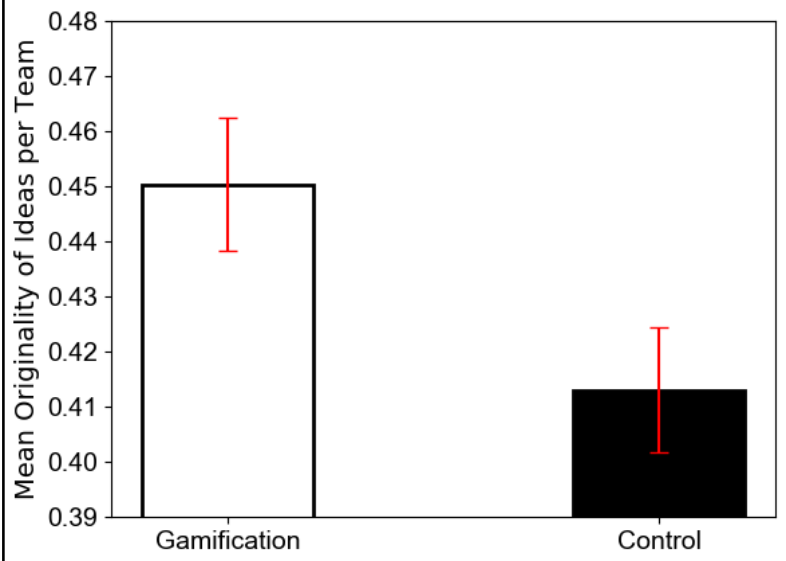

Fig. 4. Mean originality of ideas per team for the gamification and control conditions. Teams in the gamification condition generated significantly more original ideas than teams in the control condition. Standard errors are represented in the figure by the error bars attached to each column.

$p<0.05$ ), which is trivial because more people tend to produce more original ideas and, more interestingly, experimental condition $(\beta=0.29, t(63)=2.52, p<0.05)$.

\section{DISCUSSION}

Gamification has been applied in different areas including idea generation in groups [41], [35], but laboratory research on this issue is still rare. This study can be considered as unique for two reasons. First, to the author's best knowledge, this study is the first experimental study on gamified idea generation in teams and therefore it overcomes several methodological shortcomings of former quasi experiments or field studies on this issue. Secondly, in this study a practically relevant task was used for idea generation in team, which created a realistic setting for an innovative enterprise.

In general, the findings provide a strong evidence of gamification's effectivity, which previously was considered anecdotal by some scholars [35], [61]. Performance-related results provided support for $\mathrm{H} 1$ and $\mathrm{H} 2$, indicating that gamified teamwork increases the number of generated ideas as well as their originality. In terms of standardized sample effect sizes, gamification had a large effect on the number of generated ideas and a medium effect on the originality of generated ideas [78].

\section{IMPLICATIONS}

In terms of COR theory, gamification helped participants generating and regulating resources required during the experiment. As gamification mechanics were part of the task, it can be speculated that the resources were focused on work instead of being drawn to any task-unrelated activity.

The practical implications also can be drawn from the present study. Gamified teamwork for idea generation in small teams was shown to be not only effective, but also efficient. The applied procedure does not afford an additional financial investment or special skills: the used materials like moderation

TABLE V. COEFFICIENTS OF REGRESSION ANALYSIS - ORIGINALITY OF IDEAS

\begin{tabular}{|c|c|c|c|c|c|c|}
\hline \multirow{2}{*}{$\begin{array}{c}\text { Regression statistics } \\
d f\end{array}$} & \multicolumn{3}{|c|}{ Model 1} & \multicolumn{3}{|c|}{ Model 2} \\
\hline & & 5 & & & 6 & \\
\hline$R^{2}$ & & 0.11 & & & 0.20 & \\
\hline Adjusted $R^{2}$ & & 0.04 & & & 0.12 & \\
\hline$F$ & & 1.59 & & & $2.49^{*}$ & \\
\hline$\Delta R^{2}$ & & 0.11 & & & 0.08 & \\
\hline$\Delta F$ & & 1.59 & & & $6.33^{*}$ & \\
\hline$f^{2}$ & & 0.12 & & & 0.23 & \\
\hline Variables & $B$ & $S E$ & $\beta$ & $B$ & $S E$ & $\beta$ \\
\hline Constant & $0.26^{* *}$ & 0.09 & & 0.17 & 0.09 & \\
\hline Age of team members & 0.00 & 0.00 & 0.19 & 0.01 & 0.00 & 0.22 \\
\hline Sex composition of the team ${ }^{a}$ & -0.01 & 0.01 & -0.08 & -0.01 & 0.01 & -0.06 \\
\hline $\begin{array}{c}\text { Relationship duration } \\
\text { within the team (month) }\end{array}$ & 0.00 & 0.00 & 0.06 & 0.00 & 0.00 & 0.05 \\
\hline Team size & $0.04 *$ & 0.02 & 0.27 & $0.04 *$ & 0.02 & 0.29 \\
\hline $\begin{array}{c}\text { Gaming time (h/week) } \\
\text { of team members }\end{array}$ & 0.00 & 0.00 & -0.05 & 0.00 & 0.00 & -0.03 \\
\hline Experimental condition $^{\text {b }}$ & & & & $0.04 *$ & 0.02 & 0.29 \\
\hline
\end{tabular}


cards or a laptop are likely to be available in every office and are not expensive. Because of these positive effects, the implementation of gamified teamwork can be recommended for small teams generating ideas and striving for idea originality in the business context. The latter is a precondition of innovation development [15] enhancing the competitiveness of an enterprise [4], [15].

\section{LIMITATIONS AND FURTHER RESEARCH}

The crisis meeting simulation should appear to be realistic, however, it is still only an approximation of a real situation. It is plausible to assume that in a real crisis meeting the entrepreneurial team discusses the data already known by all team members, while in the present study they were new to all participants. Members of a multidisciplinary team are specialized on different areas like marketing, PR, IT etc., therefore the single experts are likely to dominate a discussion about specific problems [79]. Such knowledge differentiation can be considered in future research. Ideally, gamified teamwork following the described procedure should be tested in a real enterprise to verify the results and increase the study's external validity.

A possible follow-up study could investigate whether gamification leads to more balanced discussion contribution of team members compared to non-gamified teamwork, as it was found to have a positive effect on teamwork effectivity in innovative projects [79]. For this purpose, speech proportions and speakers' turns can be used as an operationalization of a discussion contribution.

Besides the listed covariats, personality traits like Extraversion are likely to influence the perception of gamification mechanics and as a result participants' performance in gamified teamwork [63], [35]. Investigating their impact in detail may help to understand how and for whom exactly gamified idea generation works.

\section{REFERENCES}

[1] A. Baregheh, J. Rowley, and S. Sambrook. (2009). Towards a multidisciplinary definition of innovation. Manag. Decis. [Online]. 47(8), pp. 1323-1339. Available: doi:10.1108/00251740910984578

[2] L. Alexander and D. van Knippenberg. (2014, October). Teams in pursuit of radical innovation: A goal orientation perspective. Acad. Manag. Rev. [Online]. 39(4), pp. 423-438. Available: doi:10.5465/amr.2012.0044

[3] P. G. Bain, L. Mann, and A. Pirola-Merlo. (2001, February). The innovation imperative: The relationships between team climate, innovation, and performance in research and development teams. Small Group Res. [Online]. 32(1), pp. 55-73. Available: doi: $10.1177 / 104649640103200103$

[4] A. Daghfous, "Absorptive capacity and the implementation of knowledge-intensive best practices," $S A M$, vol. 69, no. 2, pp. 21-27, Jan., 2004.

[5] U. Grissemann, A. Plank, and A. Brunner-Sperdin. (2013, June). Enhancing business performance of hotels: The role of innovation and customer orientation. Int. J. Hospit. Manag. [Online]. 33, pp. 347-356. Available: doi:10.1016/j.ijhm.2012.10.005

[6] P. W. Roberts, "Product innovation, product-market competition and persistent profitability in the US pharmaceutical industry," Strat. Manag. J., vol. 20, no. 7, pp. 655-670, Jul., 1999.

[7] W. T. Robinson. (1990, October). Product innovation and start-up business market share performance. Manag. Sci. [Online]. 36 (10), pp. 1279-1289. Available: doi: $10.1287 / \mathrm{mnsc} .36 .10 .1279$

[8] A. K. A. Ghadim, D. J. Pannell, and M. P. Burton (2005, July). Risk, uncertainty, and learning in adoption of a crop innovation. Agr. Econ.
[Online]. 33(1), pp. 1-9. Available: doi:10.1111/j.15740862.2005.00433.x

[9] S. F. Latham and M. Braun. (2009, March). Managerial risk, innovation, and organizational decline. J. Manag. [Online]. 35(2), pp. 258-281. Available: doi:10.1177/0149206308321549

[10] J. Tan. (2001, July). Innovation and risk-taking in a transitional economy: A comparative study of Chinese managers and entrepreneurs. $J$ J Bus. Vent. [Online]. 16(4), pp. 359-376. Available: doi:10.1016/S0883-9026(99)00056-7

[11] E. R. Crawford and J. A. Lepine. (2013, January). A configural theory of team processes: Accounting for the structure of taskwork and teamwork. Acad. Manag. Rev. [Online]. 38(1), pp. 32-48. Available: doi: $10.5465 / \mathrm{amr} .2011 .0206$

[12] M. A. Marks, J. E. Mathieu, and S. J. Zaccaro. (2001, July). A temporally based framework and taxonomy of team processes. Acad. Manag. Rev. [Online]. 26(3), pp. 356-376. Available: doi:10.5465/AMR.2001.4845785

[13] J. K. H. Nga and G. Shamuganathan. (2010, August). The influence of personality traits and demographic factors on social entrepreneurship start up intentions. J. Bus. Ethics. [Online]. 95(2), pp. 259-282. Available: doi:10.1007/s10551-009-0358-8

[14] G. Barczak, A. Griffin, and K. B. Kahn. (2009, January). Perspective: trends and drivers of success in NPD practices: results of the 2003 PDMA best practices study. J. Prod. Innov. Manag. [Online]. 26(1), pp. 3-23. Available: doi:10.1111/j.1540-5885.2009.00331.x

[15] L. J. Kornish and K. T. Ulrich. (2014, February). The importance of the raw idea in innovation: Testing the sow's ear hypothesis. J. Mark. Res. [Online]. 51(1), pp. 14-26. Available: doi:10.1509/jmr.12.0401

[16] F. Langerak, E. J. Hultink, and H. Robben. (2004, June). The role of predevelopment activities in the relationship between market orientation and performance. $R \& D$ Manag. [Online]. 34(3), pp. 295-309. Available: doi:10.1111/j.1467-9310.2004.00340.x

[17] P. B. Paulus and H.-C. Yang. (2000, May). Idea generation in groups: A basis for creativity in organizations. Organ. Behav. Hum. Decis. Process. [Online]. 82(1), pp. 76-87. Available: doi:10.1006/obhd.2000.2888

[18] F. R. da Silva, R. Fabrício, R. da Silva Pinto, N. V. Galegale, and G. Akabane. (2015, May). Why technology-based startups fail? An IT management approach. Presented at the Production and Operations Management Society 26th Annual Conference. [Online]. Available: https://www.pomsmeetings.org/ConfProceedings/060/Full\%20Papers/Fi nal\%20Full\%20papers/060-0879.pdf

[19] M. A. Gurdon and K. J. Samsom. (2010, March). A longitudinal study of success and failure among scientist-started ventures. Technovation. [Online]. 31(3), pp. 219-234. Available: doi: 10.1016/j.technovation.2009.10.004

[20] J. Kummer, T. Funke, A.-G. Amrhein, and M. Müller. (2016, January). Gründungen scheitern nicht am Team, sondern im Team. Studie zu Herausforderungen für Startup-Teams [New ventures fail not because of the team, but in team. A study on challenges for startup teams]. RKW Kompetenzzentrum. Eschborn. [Online]. Available: https://www.rkwkompetenzzentrum.de/gruendung/studie/gruendungen-scheitern-nichtam-team-sondern-im-team/

[21] Z. J. Acs, S. Desai, and J. Hessels. (2008, October). Entrepreneurship, economic development and institutions. Small Bus. Econ. [Online]. 31(3), pp. 219-234. Available: doi:10.1007/s11187-008-9135-9

[22] A. Hidalgo and J. Albors. (2008, March). Innovation management techniques and tools: a review from theory and practice. $R \& D$ Manag. [Online]. 38(2), pp. 113-127. Available: doi:10.1111/j.14679310.2008.00503.x

[23] R. Owen, J. Stilgoe, P. Macnaghten, M. Gorman, E. Fisher, and D. Guston, "A framework for responsible innovation," in Responsible Innovation: Managing the Responsible Emergence of Science and Innovation in Society, 1st ed., R. Owen, J. Bessant and M. Heintz, Eds. Chichester, United Kingdom: John Wiley \& Sons, Ltd, 2013, ch. 2, pp. $27-50$.

[24] A. F. Osborn, Applied imagination, 1st ed. New York: Scribner, 1953.

[25] K. Byron. (2012, July). Creative reflections on brainstorming. Lond. Rev. Educ. [Online]. 10(2), pp. 201-213. Available: doi: $10.1080 / 14748460.2012 .691284$

[26] Z. Ghabanchi and S. Behrooznia. (2014, May). The impact of brainstorming on reading comprehension and critical thinking ability of 
EFL learners. Procedia - Social and Behavioral Sciences. [Online]. 98, pp. 513-521. Available: doi:10.1016/j.sbspro.2014.03.447

[27] V. R. Brown and P. B. Paulus, "Making group brainstorming more effective: Recommendations from an associative memory perspective," Curr. Dir. Psychol. Sci., vol. 11, no. 6, pp. 208-212, Dec., 2002.

[28] B. A. Nijstad, W. Stroebe, and H. F. Lodewijkx (2003, November). Production blocking and idea generation: Does blocking interfere with cognitive processes?. J. Exp. Soc. Psychol. [Online]. 39(6), pp. 531-548. Available: doi:10.1016/S0022-1031(03)00040-4

[29] E. F. Rietzschel, B. A. Nijstad, and W. Stroebe, "Productivity is not enough: A comparison of interactive and nominal brainstorming groups on idea generation and selection," Journal of Experimental Social Psychology, vol. 42, no. 2, pp. 244-251, Mar., 2006.

[30] A. L. Delbecq, A. H. van de Ven, and D. H. Gustafson, "Guidelines for conducting NGT meetings," in Group techniques for program planning: A guide to nominal group and Delphi processes, 1st ed. Middleton: Green Briar Press, 1975, ch. 3, pp. 40-82.

[31] M. Gallagher, T. Hares, J. Spencer, C. Bradshaw, and I. Webb (1993, March). The nominal group technique: a research tool for general practice?. Fam. Pract. [Online]. 10(1), pp. 76-81. Available: doi:10.1093/fampra/10.1.76

[32] J. Rohrbaugh (1981, October). Improving the quality of group judgment: Social judgment analysis and the nominal group technique. Organ. Behav. Hum. Perf. [Online]. 28(2), pp. 272-288. Available: doi:10.1016/0030-5073(81)90025-8

[33] P. B. Pauhus, M. T. Dzindolet, G. Poletes, and L. M. Camacho (1993, February). Perception of performance in group brainstorming: the illusion of group productivity. Pers. Soc. Psychol. Bull. [Online]. 19(1), pp. 78-89. Available: doi:10.1177/0146167293191009

[34] S. Deterding, D. Dixon, R. Khaled, and L. Nacke. (2011, September). From game design elements to gamefulness: defining gamification. Presented at the 15th international academic MindTrek conference: Envisioning future media environments. [Online]. Available: doi:10.1145/2181037.2181040

[35] J. Hamari, J. Koivisto, and H. Sarsa. (2014, January). Does gamification work? A literature review of empirical studies on gamification. Presented at the 47th Hawaii International Conference on System Science. [Online]. Available: doi:10.1109/HICSS.2014.377

[36] C. Cheong, F. Cheong, and J. Filippou. (2013, June). Quick Quiz: A Gamified Approach for Enhancing Learning. Presented at the Pacific Asia Conference on Information Systems (PACIS). [Online]. Available: http://www.pacis-net.org/file/2013/PACIS2013-206.pdf

[37] D. Dicheva, C. Dichev, G. Agre, and G. Angelova, "Gamification in education: a systematic mapping study," J. Educ. Techno. Soc., vol. 18, no. 3, pp. 75-88, Jul., 2015.

[38] F. Khatib et al. (2011, September). Crystal structure of a monomeric retroviral protease solved by protein folding game players. Nat. Struct. Mol. Biol. [Online]. 18(10), pp. 1175-1177. Available: doi: $10.1038 / \mathrm{nsmb} .2119$

[39] G. Zicherman and J. Linder, The gamification revolution: how leaders leverage game mechanics to crush the competition, USA: McGraw-Hill Education, 2013.

[40] J. McGonigal, SuperBetter: How a gameful life can make you stronger, happier, braver and more resilient, 1st ed. New York: Penguin Press, 2015

[41] E. F. Rietzschel, B. A. Nijstad, and W. Stroebe, "Productivity is not enough: A comparison of interactive and nominal brainstorming groups on idea generation and selection," Journal of Experimental Social Psychology, vol. 42, no. 2, pp. 244-251, Mar., 2006.

[42] A. Moradian, M. Nasir, K. Lyons, R. Leung, and S. E. Sim. (2014, April). Gamification of collaborative idea generation and convergence. Presented at the the 32nd annual ACM conference on human factors in computing [Online]. Avstems. Available: doi: $10.1145 / 2559206.2581253$

[43] S. Roth, D. Schneckenberg, and C. W. Tsai. (2015, June). The ludic drive as innovation driver: Introduction to the gamification of innovation. Creat. Innov. Manag. [Online]. 24(2), pp. 300-306. Available: doi:10.1111/caim.12124

[44] C. W. Scheiner. (2015, June). The motivational fabric of gamified idea competitions: The evaluation of game mechanics from a longitudinal perspective. Creat. Innov. Manag. [Online]. 24(2), pp. 341-352. Available: doi:10.1111/caim.12115
[45] S. G. Cohen and D. E. Bailey, "What makes teams work: Group effectiveness research from the shop floor to the executive suite," $J$. Manag., vol. 23, no. 3, pp. 239-290, Jun., 1997.

[46] N. R. Anderson and M. A. West, "Measuring climate for work group innovation: development and validation of the team climate inventory," J. Organ. Behav., vol. 19, no. 3, pp. 235-258, May, 1998.

[47] L. Zhou and D. Zhang. (2006, April). A comparison of deception behavior in dyad and triadic group decision making in synchronous computer-mediated communication. Small Group Res. [Online]. 37(2), pp. 140-164. Available: doi:10.1177/1046496405285125

[48] T. Kollmann, C. Stöckmann, S. Hensellek, and J. Kensbock. (2017, October). Deutscher Startup Monitor. Mut und Macher [German Startup Monitor. Courage and Doer]. KPMG. Germany. [Online]. Available: http://deutscherstartupmonitor.de/fileadmin/dsm/dsm17/daten/dsm 2017.pdf

[49] E. Salas, M. L. Shuffler, A. L. Thayer, W. L. Bedwell, and E. H. Lazzara. (2015, July/August). Understanding and improving teamwork in organizations: A scientifically based practical guide. Hum. Resour. Manag. [Online]. 54(4), pp. 599-622. Available: doi:10.1002/hrm.21628

[50] B. B. Morgan Jr., E. Salas, and A. S. Glickman. (1993, March). An Analysis of Team Evolution and Maturation. J. Gen. Psychol. [Online]. 120(3), pp. 277-291. Available: doi:10.1080/00221309.1993.9711148

[51] E. Dahan and H. Mendelson. (2001, January). An extreme-value model of concept testing. Manag. Sci. [Online]. 47(1), pp. 102-116. Available: doi: $10.1287 / \mathrm{mnsc} .47 .1 .102 .10666$

[52] M. Diehl and W. Stroebe. (1987, September). Productivity loss in brainstorming groups: Toward the solution of a riddle. J. Pers. Soc. Psychol. [Online]. 53(3), pp. 497-509. doi:10.1037/0022-3514.53.3.497

[53] K. Girotra, C. Terwiesch, and K. T. Ulrich. (2010, April). Idea generation and the quality of the best idea. Manag. Sci. [Online]. 56(4), pp. 591-605. Available: doi:10.1287/mnsc. 1090.1144

[54] M. Renko, A. Carsrud, and M. Brännback, "The effect of a market orientation, entrepreneurial orientation, and technological capability on innovativeness: A study of young biotechnology ventures in the United States and in Scandinavia," J. Small Bus. Manag., vol. 47, no. 3, pp. 331-369, Jul., 2009.

[55] J. Huizinga, Homo Ludens. A Study of the Play-Element in Culture, vol. 86. London, England: Routledge and Kegan Paul Ltd, 2009

[56] J. Nakamura and M. Csikszentmihalyi, "Flow theory and research," in Oxford Handbook of Positive Psychology, 2nd ed., S. J. Lopez and C. R. Snyder. United States of America: McGraw-Hill, 2009, pp. 195-206.

[57] T. M. Amabile, "A model of creativity and innovation in organizations," Res. Organ. Behav., vol. 10, no. 1, pp. 123-167, 1988

[58] N. Lehmann-Willenbrock and J. A. Allen. (2014, November). How fun are your meetings? Investigating the relationship between humor patterns in team interactions and team performance. J. Appl. Psychol. [Online]. 99(6), pp. 1278-1287. Available: doi:10.1037/a0038083

[59] C. Mainemelis and S. Ronson. (2006). Ideas are born in fields of play: Towards a theory of play and creativity in organizational settings. Res. Organ. Behav. [Online]. 27, pp. 81-131. Available: doi:10.1016/S01913085(06)27003-5

[60] S. E. West, E. Hoff, and I. Carlsson, "Play and productivity: enhancing the creative climate at workplace meetings with play cues," Am. J. Play, vol. 9, no. 1, pp. 71-86, 2016.

[61] C. A. Petelczyc, A. Capezio, K. T. Wang, S. L. D. Restubog, and K. Aquino. (2018, January). Play at Work: An Integrative Review and Agenda for Future Research. J. Manag. [Online]. 44(1), pp. 161-190. Available: doi:10.1177/0149206317731519

[62] S. E. Hobfoll. (2001, July). The influence of culture, community, and the nested-self in the stress process: advancing conservation of resources theory. Appl. Psychol. [Online]. 50(3), pp. 337-421. Available: doi:10.1111/1464-0597.00062

[63] D. Codish and G. Ravid, "Academic course gamification: The art of perceived playfulness," Interdisc. J. of E-Learning and Learning Obj., vol. 10, pp. 131-151, 2014.

[64] R. Cózar-Gutiérrez and J. M. Sáez-López. (2016, February). Gamebased learning and gamification in initial teacher training in the social sciences: an experiment with MinecraftEdu. Int. J. Educ. Techno. Higher Educ. [Online]. 13(1), pp. 1-11. Available: doi:10.1186/s41239016-0003-4 
[65] L. De-Marcos, A. Domínguez, J. Saenz-de-Navarrete, and C. Pagés, “An empirical study comparing gamification and social networking on elearning," Comput. Educ., vol. 75, pp. 82-91, 2014.

[66] B. Gnauk, L. Dannecker, and M. Hahmann. (2012, March). Leveraging gamification in demand dispatch systems. Presented at the 2012 Joint EDBT/ICDT workshops. [Online]. Available: doi:10.1145/2320765.2320799

[67] O. Harari and W. K. Graham. (1975). Tasks and task consequences as factors in individual and group brainstorming. The J. Soc. Psychol. [Online]. 95(1), pp. 61-65. Available: doi:10.1080/00224545.1975.9923234

[68] D. Brenner and F. Brenner, Assessment Center, vol. 3. Offenbach, Germany: GABAL Verlag GmbH, 2010

[69] B. Rammstedt and O. P. John, "Kurzversion des big five inventory (BFIK) [Short version of the big five inventory (BFI-K)]," Diagnostica, vol. 51, no. 4, pp. 195-206, Oct., 2005.

[70] N. Jakoby and R. Jacob, "Messung von internen und externen Kontrollüberzeugungen in allgemeinen Bevölkerungsumfragen [Measurement of the external and internal locus of control in general population by surveys]," Zentrum für Umfragen, Methoden und Analysen: Nachrichten, vol. 45, no. 23, pp. 61-71, 1999.

[71] M. Roth and P. Y. Herzberg. (2004). A Validation and Psychometric Examination of the Arnett Inventory of Sensation Seeking (AISS) in German Adolescents. Eur. J. Psychol. Assess. [Online]. 20(3), pp. 205214. Available: doi:10.1027/1015-5759.20.3.205

[72] M. Roth and D. Mayerhofer. (2014). Deutsche Version des Arnett Inventory of Sensation Seeking (AISS-d) [German version of the Arnett Inventory of Sensation Seeking (AISS-d)]. Leibniz-Institut für Sozialwissenschaften. Germany [Online]. Available: doi: 10.6102/zis73
[73] F. B. Zapkau, C. Schwens, H. Steinmetz, and R. Kabst. (2015, March). Disentangling the effect of prior entrepreneurial exposure on entrepreneurial intention. J. Bus. Res. [Online]. 68(3), pp. 639-653. Available: doi:10.1016/j.jbusres.2014.08.007

[74] M. K. Poetz and M. Schreier. (2012, March). The value of crowdsourcing: can users really compete with professionals in generating new product ideas?. Journal of Product Innovation Management. [Online]. 29(2), pp. 245-256. Available: doi:10.1111/j.1540-5885.2011.00893.x

[75] M. A. Wallach and N. Kogan, Modes of thinking in young children: A study of the creativity-intelligence distinction. Oxford, England: Holt, Rinehart \& Winston, 1965.

[76] K. Krippendorff, Content analysis: An introduction to its methodology, 2nd ed. Thousand Oaks, CA: Sage, 2004

[77] J. T. Cacioppo, J. R. Priester and G. G. Berntson "Rudimentary determinants of attitudes: II. Arm flexion and extension have differential effects on attitudes," J. Pers. Soc. Psychol., vol. 65, no. 1, pp. 5-17, Jul., 1993.

[78] J. Cohen, Statistical power analysis for the behavioral sciences, 2nd ed. New York: Lawrence Earlbaum Associates, 1988.

[79] M. Hoegl and H. G. Gemuenden. (2001, July/August). Teamwork quality and the success of innovative projects: A theoretical concept and empirical evidence. Organ. Sci. [Online]. 12(4), pp. 435-449. Available: doi:10.1287/orsc.12.4.435.10635 